Article

\title{
Italy and China Sharing Best Practices on the Sustainable Development of Small Underground Settlements
}

\author{
Laura Genovese ${ }^{1,+}$, Roberta Varriale ${ }^{2, \dagger}$, Loredana Luvidi ${ }^{3, *, \dagger}$ and Fabio Fratini ${ }^{4, \dagger}$ \\ 1 CNR - Institute for the Conservation and the Valorization of Cultural Heritage, 20125 Milan, Italy; \\ laura.genovese@cnr.it \\ 2 CNR-Institute of Studies on Mediterranean Societies, 80134 Naples, Italy; roberta.varriale@issm.cnr.it \\ 3 CNR-Institute for the Conservation and the Valorization of Cultural Heritage, \\ 00015 Monterotondo St., Italy \\ 4 CNR-Institute for the Conservation and the Valorization of Cultural Heritage, 50019 Sesto Fiorentino, Italy; \\ fabio.fratini@cnr.it \\ * Correspondence: loredana.luvidi@cnr.it; Tel.: +39-06-90672887 \\ + These authors contributed equally to this work.
}

Received: 28 December 2018; Accepted: 5 March 2019; Published: 8 March 2019

check for updates

\begin{abstract}
Both Southern Italy and Central China feature historic rural settlements characterized by underground constructions with residential and service functions. Many of these areas are currently tackling economic, social and environmental problems, resulting in unemployment, disengagement, depopulation, marginalization or loss of cultural and biological diversity. Both in Europe and in China, policies for rural development address three core areas of intervention: agricultural competitiveness, environmental protection and the promotion of rural amenities through strengthening and diversifying the economic base of rural communities. The challenge is to create innovative pathways for regeneration based on raising awareness to inspire local rural communities to develop alternative actions to reduce poverty while preserving the unique aspects of their local environment and culture. In this view, cultural heritage can be a catalyst for the sustainable growth of the rural community. Through a series of projects on a national and international scale, the authors have addressed some of these problems by exchanging best practices in conservation, sustainable use and the enhancement of the underground heritage.
\end{abstract}

Keywords: underground settlements; earthen architecture; conservation; regeneration; enhancement

\section{Introduction}

The Italian and Chinese rural villages studied are the result of successful and sustainable balancing attempts between maximization of environmental opportunities and minimization of natural conflicts and social interactions in karst habitat. Both locations represent 'troglodyte or negative building culture' which is characterized by the systematic application of building techniques based on quarrying and removal rather than the vertical use of shaped rocks, bricks or various mixtures. It is a worldwide modus aedificandi which was developed during prehistoric times and is still in use today: this long lasting building approach is one of the most typical building techniques in plateaus located between latitude $34^{\circ}$ and $40^{\circ}$ North (Figure 1). In this particular climatic zone, surprisingly, underground sections of historical excavated settlements are very similar to each other. Based on the study of historical artifacts excavated below the ground level, it appears that local building know-how was reconsidered and new underground building skills were adopted. Thus, underground architecture of worldwide troglodyte settlements has much more in common than their corresponding above-ground 
building styles. This is the case because the underground world interprets raw materials with the adoption of essential shapes in response to natural forces and produces significant artifacts with strong identity and distinctive features responding to local culture.

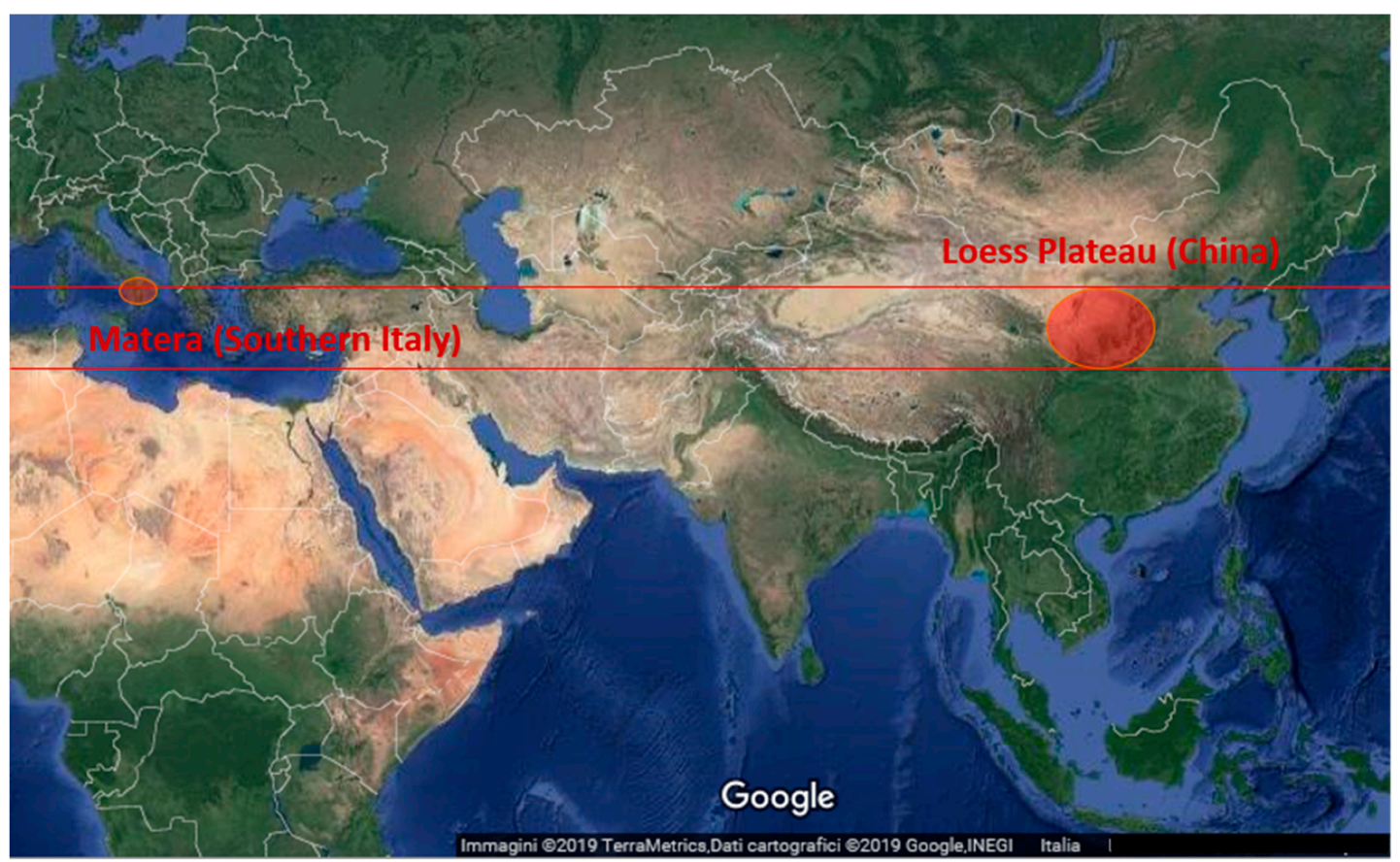

Figure 1. Map of the case studies: in evidence, the typical climatic zone of the excavated villages (Southern Italy and Loess plateau in China are shown in red).

The underground architecture was also recently investigated within VerSus (Vernacular Knowledge for Sustainable Architecture), a European project developed in the framework of the Culture 2007-2013 program, which had partners CRAterre-Ecole Nationale Supérieure d'Architecture de Grenoble (France), Escola Superior Gallaecia (Portugal), DIDA (Department of Architecture, University of Florence-Italy), DDICAAR (Department of Civil Engineering, Environment and Architecture, University of Cagliari-Italy), Escuela Técnica Superior de Arquitectura of Polytechnic University of Valencia, Spain [1].

Since, by definition, the term Underground Built Heritage (UBH) refers to historical artifacts excavated in underground areas that become significant expressions of local cultural heritage, troglodyte villages are perfect case studies since they house the strongest concentration of historical artifacts excavated to manage urban functions [2]. The Loess Plateau yaodong villages ( $36^{\circ} 52^{\prime} 59.99^{\prime \prime} \mathrm{N}$, $\left.108^{\circ} 42^{\prime} 59.99^{\prime \prime} \mathrm{E}\right)$ and the excavated villages in Southern Italy $\left(40^{\circ} 40^{\prime} 11.39^{\prime \prime} \mathrm{N}, 16^{\circ} 35^{\prime} 50.03^{\prime \prime} \mathrm{E}\right)$ represent two of the most significant underground settlements in the world. A comparative analysis can provide new insight by testing the theories related to the connections between cultural identity and climatic zone, as well as verifying the differences and possible future actions aimed towards the enhancement and valorization of Western and Eastern excavated villages (Figure 2a,b).

This paper is based on some research by the authors on a national and international scale [3]. More specifically, on one hand, it is a National Research Council of Italy (CNR) interdepartmental project that began in 2015 coordinated by the CNR-Institute of Studies on Mediterranean Societies (ISSM) that concerns the analysis of underground settlements in Southern Italy, aiming to define good practices for their recovery, refunctionalization and enhancement [4]. On the other hand, it is a bilateral project that began in 2016, coordinated by the CNR and Institute for the Conservation and the Valorization of Cultural Heritage (ICVBC) together with the Chinese Academy of Cultural Heritage $(\mathrm{CACH})[5]$ and is related to the sharing of good practices between Italy and China for the conservation of monuments and sites in earthen material. Finally, the paper collects the results of 
a collaboration that was recently born of the authors with the World Heritage Institute of Training and Research-Asia and Pacific (WHITRAP) under the auspices of UNESCO to survey, analyze and disseminate the knowledge on small historical settlements, including the Chinese yaodong, and raise awareness about the importance of their conservation within their historical and natural landscape.

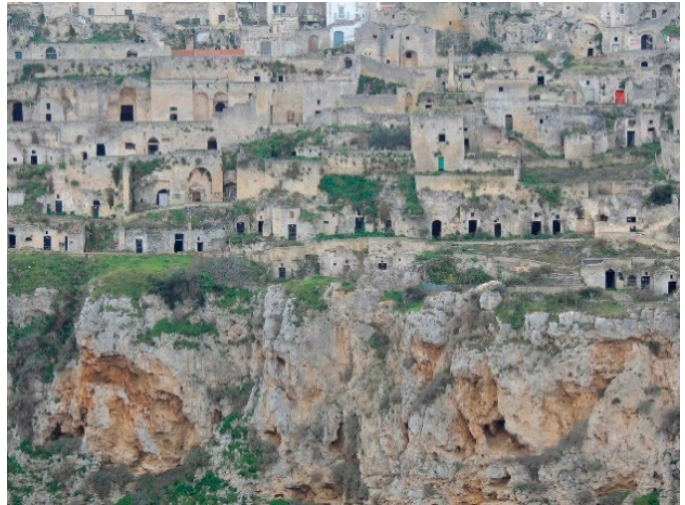

(a)

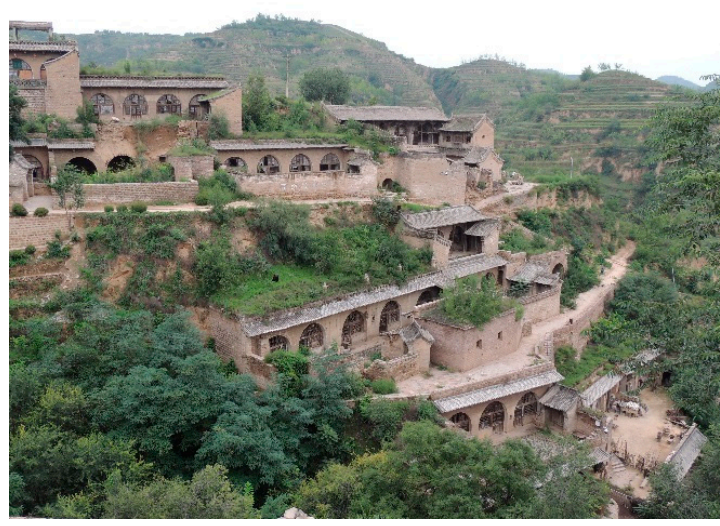

(b)

Figure 2. (a) Matera in Southern Italy, view from the eastern side of the gorge and (b) Lijiashan village on the Loess Plateau, China (by F.F., 2017).

Based on the hypothesis that both underground settlements resulted from the use of the negative building culture to cope with or solve common environmental and social problems, the paper compares the historical uses and the contemporary valorization processes carried out in Italy and China while proposing mutual exchanges between eastern and western approaches.

\section{Southern Italy and Loess Plateau Underground Settlements, Closer than Believed}

Matera is a relevant example in Southern Italy of an architectural and landscape ensemble resulting from a process of urban growth in symbiosis with nature (Figure 2a). As a matter of fact, the development of the town was by no means accidental, however rather it was the outcome of human ingenuity and a carefully thought out process. The old town of Matera (Sassi di Matera) that was developed entirely on the western side of the homonymous canyon, locally referred to as gravina (gorge), deeply erodes the Murgia, the carbonate platform that constitutes part of the province of Matera and a wide part of the Puglia region. Its precise geographical location was determined in view of the different lithological characteristics of the two sides of the valley. The stratigraphic sequence presents two geological formations: at the bottom, we find the Altamura limestone which is of Cretaceous age and is a very compact and hard stone, making it difficult to excavate and work with, while the top is characterized by gravina Calcarenite, a "calcareous tufa" which is of Upper Pliocene-Pleistocene age and is soft and easy to excavate while ensuring high stability [6,7]. On the western side of the gorge, the calcarenite crops out with a greater thickness than on the eastern side, which is why on that side of the valley, caves were being dug as early as ancient times, often obliquely. In this way, during the winter season when the sun's rays are more oblique, sunlight and heat could penetrate from the top to the bottom of the walls, while in summer when the sun's rays are almost perpendicular to the ground, only the entrance of the hypogea would be affected, leaving the dwelling fresh and humid.

In the Sassi of Matera, there are many churches and hermitages, many of which have beautiful wall paintings that tell the story and religiosity of a simple life rich in faith [8]. Most of these churches date back to the High Middle Ages to the period when the region was disputed between the Byzantine and Longobard dominions and an important phenomenon was affirmed in the Christian society of the time: monasticism. Unfortunately, these paintings have conservation problems due to water infiltrations and biological growths. These conservation issues have been addressed by Italian scholars [9], however these are problems that are common to other sites on the planet, problems that have been addressed in 
international conferences $[10,11]$. The Sassi are the result of a collective architecture that has developed over the centuries, starting with the cave houses and progressively evolving with the addition of external rooms utilizing the same excavation material and, finally, with the diffusion of entirely built houses $[12,13]$.

For centuries, the Sassi have been an example of an eco-sustainable urban agglomeration: the system of water collection tunnels in fact served as a conveyor of this precious element in the tanks, however also as a "collector" of rainwater during heavy rains, therefore limiting the erosion of the slopes to a minimum. Digging in itself reduced the consumption of soil to a minimum; the resource was exploited to the maximum to include hanging gardens on the roofs of the cave houses. In the dry season, moreover, during the night, the excavated cavities served the purpose of aspirators of atmospheric humidity that condenses in the terminal tank of the hypogea, which is always full, even if it is not connected with external channels.

The Chinese case study instead consists of a system of small rural settlements scattered throughout central China on the Loess Plateau (Figure 2b). This area extends for $640,000 \mathrm{~km}^{2}$, covering most parts of the provinces of Shaanxi and Shanxi and it comprises parts of Gansu, Ningxia and Inner Mongolia. The plateau was formed by the deposition of very fine particles of soil blown in by windstorms over thousands of years. As a result, the ground here is very fine and loamy and is highly fertile, easy to farm and dig [14,15]. Despite the high erodibility, the Plateau's terrains have the characteristic of being pseudo coherent, i.e., they can be excavated, and the cavities are more or less self-sustaining. Thanks to this property, the Loess Plateau has been historically inhabited, forming one of the earliest cradles of Chinese civilization.

The yaodong (窑洞) are a type of underground space with a varied function, constituting the minimal unit in which innumerable rural villages are organized in the Plateau's area. Without this specific type of ground, there would be no yaodongs: thanks to this ground quality, yaodongs can be carved out of the wrinkled landscape and be insulated from cold winters and hot summers.

The most common type of yaodong is dug on the faces and slopes of the plateau and presents terraces for crops. They are located in regions on the edges of the Loess Plateau, while on the inner areas where there are no hillsides and ravines, peasants dug a square pit in the ground and then dug the dwellings horizontally on the four walls to form a central, sunken courtyard or pit dwelling (siheyuan). The entrance to these pit houses is usually through a ramp or an underground corridor.

Typically, a yaodong has a long vaulted room with a semicircular entrance closed by walls, built with fired bricks, earth bricks, stones and wood, depending on the specific site conditions, and is covered with a wooden door or a quilt. This arch-shaped structure also allows the sun to further penetrate inside the cave in winter, therefore making full use of solar radiation.

A third type of dwelling is the hoop yaodong ( gūyáo) or independent yaodong. This kind of cave house is generally built in those areas where bedrock that is exposed on top of the hill makes excavation somewhat difficult and motivates the construction of houses wholly above ground (Figure 3). Otherwise, if these hold on the slope of the hill, they are only partially excavated and are inspired by the typical underground dwellings' shape.

Usually, the roof is made of stone flakes covered with earth to ensure thermal insulation of the interiors. Alternatively, the underground yaodong houses have a thick layer of earth on top (about 3 to $5 \mathrm{~m}$ deep) which acts as an effective insulation coverage and humidity modulator (Figure 4). Above the yaodongs, there are often little chimneys and a tunnel constructed in the earth. These two features, together with a small ventilation window that is kept open in the façade, represent the breathing system of a yaodong. They work on the properties of hot air rising to achieve natural air circulation inside and to drive out humidity. The inner space is usually utilized in more than one way: the main living room, kitchen and sometimes bedroom (Figure 5a). The brazier for cooking also serves as a heating element for the environment and for the adobe brick bed ( $k a n g)$ attached to it. The toilet is a stand-alone unit located outside of the cave, making it rather inconvenient on cold or rainy days. 


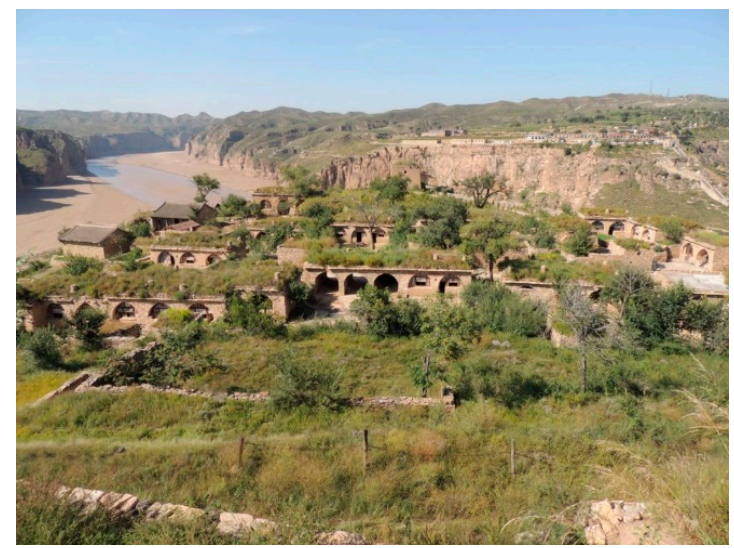

Figure 3. Laoniuwan village in Shanxi Province (China). A general view of hoops yaodongs, (by F.F. and L.L., 2017).

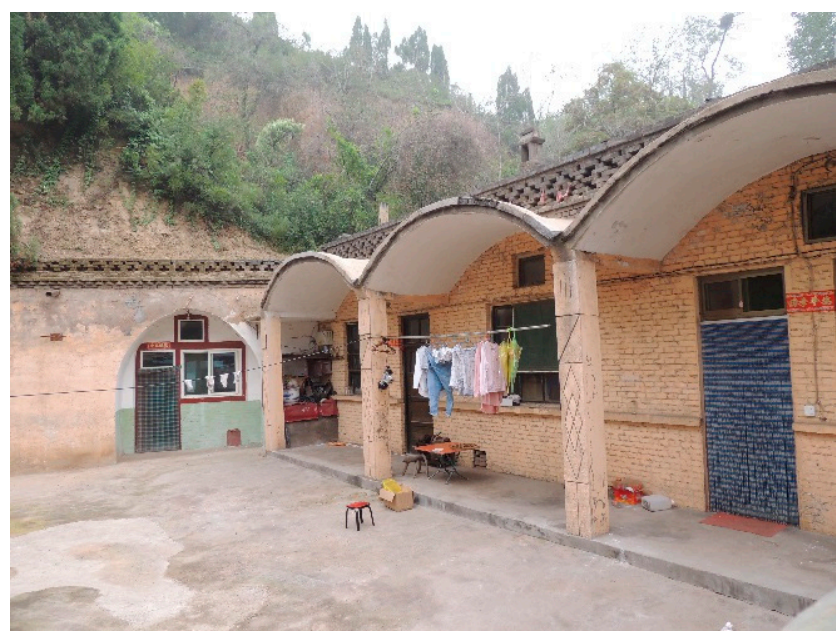

Figure 4. Underground village around the Wang Family Compound in Shanxi Province (China). New cave dwellings have been built in yaodong style annexed to the traditional ones that have been partially abandoned or adapted to the needs of modern life (by F.F. and L.L., 2017).

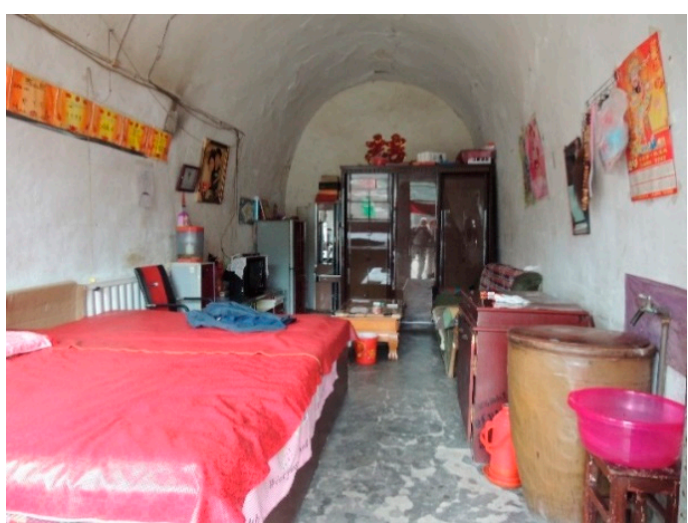

(a)

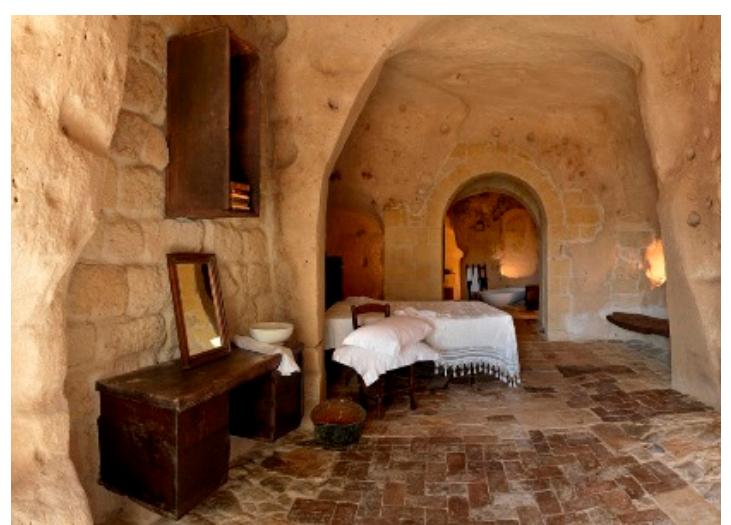

(b)

Figure 5. (a) Qikou town in Shanxi Province (China), the interior of a traditional yaodong adapted to modern life (by F.F. and L.L., 2017); (b) Matera in Southern Italy, Re-interpretation of accommodation in excavated rooms in a luxury hotel (by R.V., 2018).

Often multiple dwellings are built adjacent to or on top of one another and are connected together to form a multi-tiered village, often for a single clan or an extended family. Nevertheless, dwellings 
are hidden in natural alcoves that are not easily visible. Thus, it is said that "no house was seen in the whole village and no people were seen, but only trees". In fact, the architecture of a yaodong village is not about adding to, however is rather about subtracting from the earth. Indeed, all the materials required for building a yaodong can be found in the local area.

The construction of a traditional yaodong merely produces natural waste for the environment. Everything is natural and produced locally, making these houses one of the most eco-friendly in China, and they constitute the very expression of local geo-climatic conditions and traditional customs. There are greatly significant ways in which yaodong villages can integrate with nature with minimal impact.

The daily activities at a yaodong include everyday maintenance such as hardening the yaodong's earth after rainfall, ensuring proper air circulation in summer, firing a kang in winter to keep the earth dry and stable, scraping off from $500 \mathrm{~mm}$ to $1000 \mathrm{~mm}$ of eroded soil every 10 or more years and so on. The longer a yaodong is inhabited, the harder and more stable the earth becomes.

Although during ancient times, many of these villages prospered thanks to the fertility of the land, centuries of deforestation and over-grazing, exacerbated by China's population increase, have resulted in degenerated ecosystems, desertification and poor local economies with the consequence of the abandonment of the village. Just as in Southern Italy (Figure 6a), around the middle of the last century, these vernacular buildings were often abandoned because they were considered unhealthy and, above all, regarded as hopelessly outdated compared to the living standards of a "modern" city dweller.

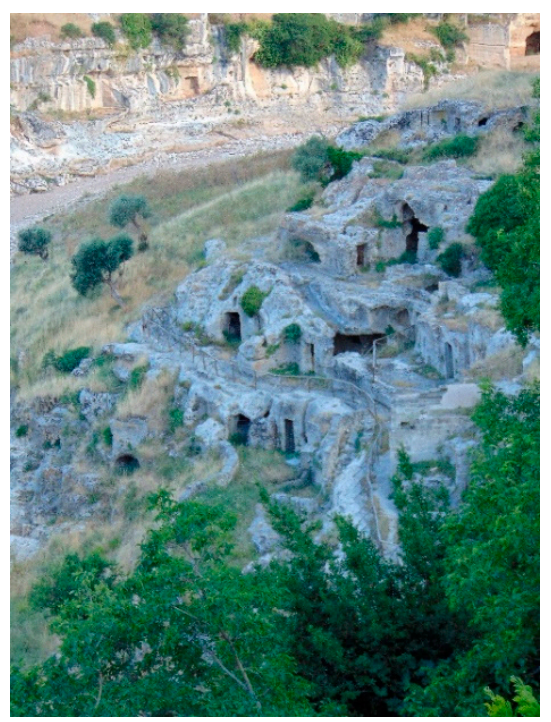

(a)

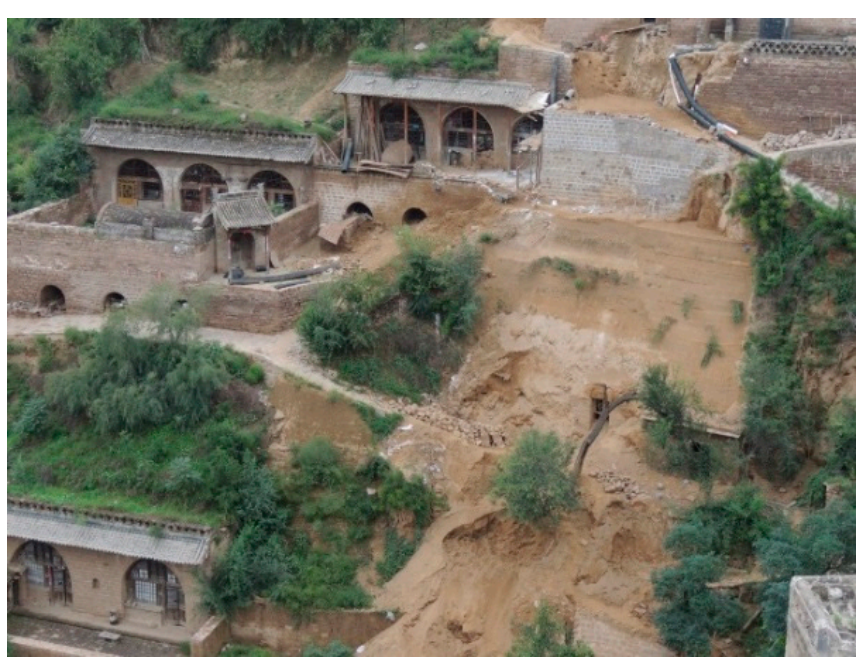

(b)

Figure 6. (a) Ginosa abandoned settlement in Southern Italy Plateau (by R.V., 2018); (b) Lijiashan Village in Shanxi Province (China): renovation work in traditional houses (by F.F. and L.L., 2017).

In recent years, many of the residents have moved to big cities in search of work and nowadays, only a few villagers remain in the Plateau's settlements. It has been estimated that 90 thousand villages disappear annually.

Some rehabilitation projects that have been carried out over the years were ineffective. Recently, there have been a few cases where survival was possible by attracting tourism and converting some of the traditional houses into affordable accommodation for tourists (Figure 6b). Nevertheless, many problems still restrict the sustainable development of this resource and could possibly compromise the material and immaterial heritage of the site.

Considering that earth architecture is particularly subject to decay processes, both systems of underground settlements must be monitored to ensure their conservation over time. For this reason, 
they require constant maintenance not only from a safety point of view, however also to guarantee their actual functionality, a prerequisite to ensure that this architecture continues to be inhabited and built.

In particular, the factors of earth structure decay are: internal factors due to structural defects and external factors such as the action of water and the type of use. Earth material is particularly sensitive to the action of water because water tends to make earth plastic again with consequent loss of the mechanical characteristics of resistance and rigidity. Water acts both as an erosive agent (rain) and through capillary action, therefore damp rises with the consequent disaggregation phenomena. The decay phenomena of the earth architecture includes superficial decay of physical and biological nature, loss of material, strong decay of the material through deep cracking or partial fall of the masonries (Figure 7). In order to develop adequate measures of intervention that are non-damaging and preventive in the event of new decay phenomena, it is important to identify the actual causes of the processes and not merely intervene on a single decay aspect [16-20]. Since the factors of decay are essentially due to water action and structural problems, a preventive conservation will have to act in these two directions. With regard to water, all the solutions designed to protect buildings from the rain should avoid capillary action and infiltrations. With regard to structural problems, it is necessary to implement strategies that limit the consequences of poor connections within the walls, roof and foundations. In the case of the Loess underground dwellings, the main problems are due to the stability of the slopes where the houses are dug and to the growth of roots and vegetation. Also, in this case, preventive conservation must ensure the regulation of water, avoiding runoff on the cliffs, erosion at the base of the cliffs and infiltration above the cliffs.

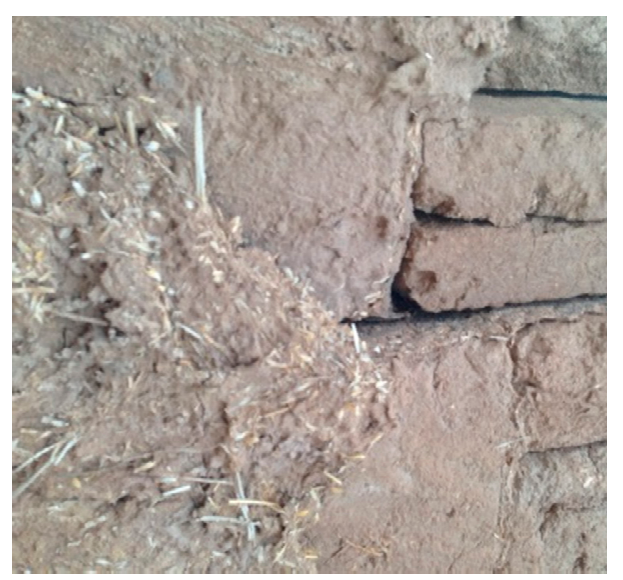

Figure 7. Lijiashan Village in Shanxi Province (China). Mud bricks made of the earth of Loess (by F.F. and L.L., 2017).

\section{The Theoretical Approach: From Historic Functions to RE-USE for Italian and Chinese Underground Settlements}

As reviewed in the previous paragraph, the Southern Italy underground settlements and Loess Plateau yaodong system seem to have much in common with reference to their morphological aspects. The application of the newborn functional classification (introduced by one of the authors for the first time at the 2018 International Conference on Urban History (EAUH) conference and not published yet [21]) to both systems strengthens this hypothesis (Figure 8). Both in Southern Italy and in Loess Plateau, in fact, underground space has historically faced environmental conflicts and has managed several social interactions, giving shape to excavated structures and artifacts that have become among the most significant expressions of local cultural heritage. 


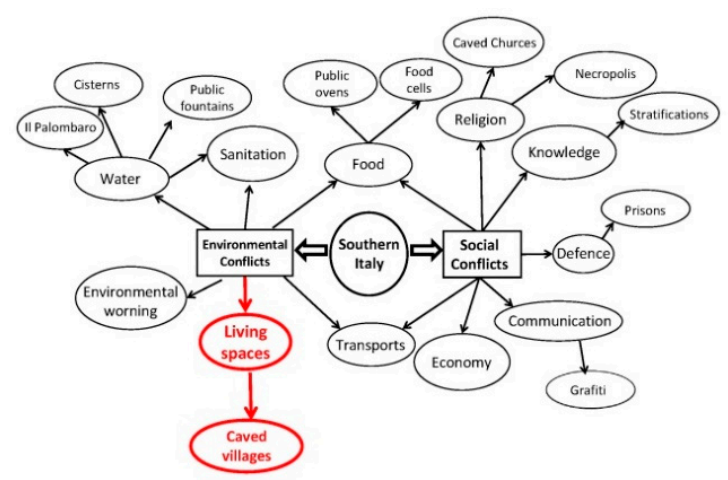

(a)

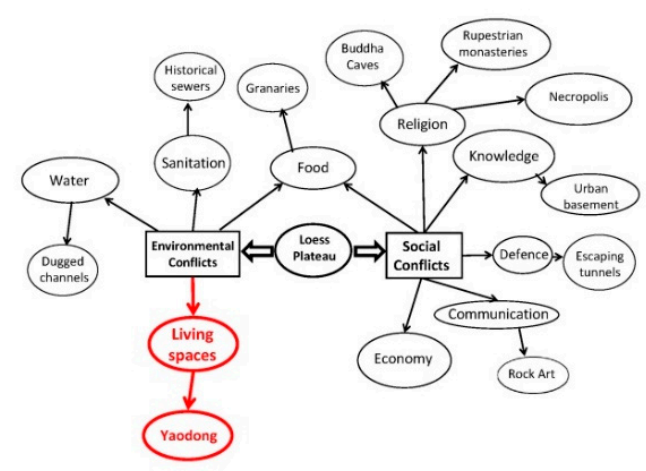

(b)

Figure 8. Underground Built Heritage (UBH) charts in Italian (a) and Chinese (b) excavated villages (by R.V.).

In both systems, the most significant elements classified under UBH are represented by the classes "water management" and "living space" with reference to the management of environmental conflicts, and by "religion", "knowledge", "defense", "communication" and "economy" with reference to the management of comparable social conflicts. Spaces excavated to manage "food" have been excavated as an answer to environmental and social problems in both countries.

The underground was historically used to collect and manage water, giving shape to significant elements of local UBH: in China channels and pools have always been excavated to optimize the distribution, mostly during the dry seasons, while in Italy, a complex system of public (cisterns, public fountains) and private water facilities (pools) completed the urban scenario. The Karst habitat and the location along communication pathways motivated negative edification of Buddha cave settlements and rupestrian monasteries in China and a complex of over 150 excavated churches in Southern Italy. In addition to being places of prayer, they also served as commercial gateways, social meeting points and as educational centers; those places strongly influenced the spreading and the consolidation of common languages for cultural exchange. The underground was excavated to create escape tunnels in China and detention prisons in Italy. In both cases, they have been strategic facilities for fortified villages or castles. Wall paintings in underground caves were used to represent social, political and religious values in both cases and such caves have always supported local, rural and urban economies. Historical tuff caves, stables, farming facilities, warehouses for local products, oil and vine transformation factories in Italy and historical steel, iron and coal mines in China, reflect the stages of the relative economies throughout history. Last, however not least, both in China and Italy, the underground has been the place for reconversion of urban waste in agriculture and today, their geological layers are open books on historic stratifications, allowing the monitoring of geological risk and soil degradation. Yaodong in China and underground settlements in Italy represent the most significant use of the underground as a living space. In both systems, public and private functions were historically managed in excavated spaces, giving shape to significant elements of UBH.

Although the application of the UBH classification to both historical systems confirms the hypothesis that artificial excavated structures can be considered as direct expressions of the underground, the analysis of the processes put in place in Italy and China for the valorization of such areas reveals substantial differences between the two countries. The application of the newborn scale of RE-USE actions for UBH to the Italian and Chinese underground settlements is the instrument used to compare the different approaches of their management, sustainable conservation, regeneration and touristic use. The newly introduced evaluation scale includes four different levels of actions carried out to address the valorization of UBH. The first three refer to innovative approaches to the various uses of historical spaces; the fourth level refers to the edification of new excavated buildings using historical skills: Re-inventing, Re-introduction, Re-interpretation and Re-building. 
Re-inventing is the level dedicated to rare and unique sites. This type of UBH requires monitoring, preservation and control processes, which are the preliminary goals, followed by Re-use actions. When Re-inventing is applicable, emphasis is also placed on the communication of historical functions, even with the use of technological instruments to promote underground culture and allow virtual reconstructions of underground life. In this case, Re-use is virtual and happens to be a significant and qualifying element of the fruition of historical sites.

Re-introduction is the level dedicated to very widespread and common historical artifacts, however is representative of local social and economic history. In these cases, restored spaces can re-host the same functions as in the past with respect to both the remains of UBH and the introduction of new standards such as those related to contemporary hygienic and security parameters.

Re-interpretation of UBH is not a conservative approach with reference to the historical functions, however it refers to the location of new ones. In these cases, the sites are restored and new functions are located while the communication of historical uses is preserved, also with the support of contemporary design which often includes historical equipment being used in interior planning (Figure 5b). Sometimes old pictures are utilized to recall the historical uses and occasionally the organization of the space includes new uses for dismissed facilities. This approach turns out to be a very stimulating challenge for architects and interior designers.

The Re-building approach includes both the replication of the historical sites, in cases of extreme danger or vulnerability of the original ones, and the use of historical negative building methods-even implemented with the adoption of new technologies and materials-within environmentally friendly urban planning. The use of underground space to position the excavated buildings has become a popular worldwide trend in the last few decades as an effect of the stimulating input given in the 60s by Malcolm Wells [22-24] who inverted guidelines of architecture for the very first time in contemporary ages. Because of his work, use and re-use of underground space was recognized as a solution to create sustainable urban development and has often been elevated in many countries to a strategic level for long-term economic and social development. The relationship between UBH and contemporary planning was a critical point for a long time. When Wout Broere [25], a worldwide famous architect specializing in underground infrastructure planning, consolidated the idea of the preservation of existing buildings and cultural heritage as a fundamental variable in underground planning, the general attitude changed; the coexistence between urban development and underground cultural heritage valorization became a priority.

The application of the RE-USE classification in the Italian and Chinese underground settlements reveals substantial differences in the approach to their management, sustainable conservation, regeneration and touristic use. This is due to two main factors.

First, while the villages of Southern Italy have been completely evacuated as an effect of the Italian Laws n.619 in 1952 and n.126 in 1967, yaodong are characterized by the coexistence of villages with continuity in use, voluntary abandonment and non-systemic evacuation. In Southern Italy, the demographic rise and the socio-economic decline of the underground built area turned those dwellings into the socio-environmental disaster described by Carlo Levi in his work "Cristo si è fermato a Eboli" (Christ stopped in Eboli) in 1946. Following the success of this book and much political pressure, Matera became the tangible, at times instrumental, symbol of the gap between Northern and Southern Italy, between urban and rural sanitary lifestyles. The fact that the city center was excavated in the underground was in itself considered to be incompatible with politically acceptable residential facilities in such a way that ground level was assumed to be the demarcation line between a politically correct approach to urban development and an unacceptable one. The Risanamento dei Sassi in Matera was part of a complex national program which included rational organization of rural areas, rural village sanitation and public investments in Southern Italy in order to support its economy and population [26]. The comparison of the two systems showed that unlike Matera, three different scenarios are possible in China: (a) currently populated villages, some of which present facilities and materials that have altered the natural equilibrium of excavated settlements; (b) abandoned and degraded yaodong and 
settlements already destroyed and (c) settlements destined to destruction to pave the way for the construction of new above ground urban settlements.

The second factor is linked to the different levels of social acceptance of underground style living in Italy and China and to the involvement of local populations in the valorization of underground settlements as cultural sites.

As an effect of the abovementioned factors, in Italy, underground sites are still perceived as poor locations, an expression of social exclusion, hygienic poverty and cultural degradation. An aboveground lifestyle in itself is considered a social upgrade, even when it requires the no-filter application of unsustainable architecture. Concrete buildings with glass and full sunlight exposure are considered the socially acceptable living standard and this perception stimulated the edification of skyscrapers in the suburbs, both in the public and in the private building sectors. Underground villages are only considered as an economic resource in the cultural and tourist sector. This attitude was also strongly influenced by the Sassi of Matera [27] which entered the UNESCO list in 1993 and are considered to be one of the most significant open air museums in the world. The recognition of Matera as the European Capital of Culture 2019 is the most evident example of how the focus of protection and enhancement measures is placed solely on the cultural value of negative building experience rather than on the potential within sustainable urban development. If one considers that even the house restored by Pietro Laureano for civil use in 2001 [28] and regarded as a symbol of contemporary sustainable use of underground Sassi as a living space was later re-transformed in a Boutique Hotel [29], the problem of gentrification seems to be a one-way process (Figure 5b).

In China, on the contrary, the widespread social housing policy and the architectural project competition has motivated academic research towards the evaluation of climatic conditions of underground settlements. Consequently, new-built yaodong villages are now believed to be at the forefront of sustainable rural development [30,31] and local communities actively participate in such projects. By way of contrast, there is little or no consideration of future touristic and cultural development of yaodong [32].

As a result, in 2014, the prestigious "Best Design Trophy", held in Taiwan, was awarded to a project that conveys the tradition of Chinese negative building, viewed as the optimal solution to the very rapid and unsustainable urbanization of recent years, while in Southern Italy, almost all actions have the purpose of enhancing cultural heritage and thus, are directed towards the valorization of UBH as new facilities for tourists and local communities.

The "Golden Pin Design Award" in Cina was the result of a long debate on sustainable construction that identified the historical typology of underground construction as the most suitable solution to the management of climate conflicts in the desert and depopulated regions of the Loess Plateau. For at least 20 years, the Chinese academic world has had a keen interest in underground settlements, mainly with the aim of recovering its value in terms of environmental sustainability, trying to replicate them in a contemporary way, as demonstrated by the new generation of yaodong.

However, the role that these rural villages had in the past is still underestimated: these rural settlements are unique cultural landscapes full of character at the core of local identity and are examples of living heritage [33,34].

That said, very recently, focus has shifted, even in China, to enhancement as a "cultural asset" and the conservation and the valorization of yaodong villages. The Chinese approach to this specific element of UBH reflects the general approach resulting from the analysis of cultural heritage policies in China in the period of 11th and 12th Five Year Plans [35]. Indeed, among the actions planned and currently being implemented, the valorization of yaodong villages is mainly seen as a function of the economic development of the sites and aims at supporting and increasing the "lost" national cultural identity. As an effect of this approach, the application of cultural policies to yaodong villages, rather than being addressed towards the conservation of the correspondent UBH, focuses on their reconstruction (after the demolition carried out during the Mao period) as instruments for the promotion of Chinese cultural identity. In this context, the envisioned future for underground 
settlements of the Loess Plateau can be a strategic backdrop to reinforce the resilience to loss of the cultural identity of the Chinese population which is not connected to troglodyte life, and is only marginally concerned for the intrinsic values of the corresponding elements of UBH.

Notwithstanding the above considerations, this approach seems nonsensical considering that underground locations are typical of Chinese cultural heritage and not Italian heritage. This difference is strikingly apparent when considering the relative weight of troglodyte character present in the sites listed by UNESCO: 54 sites in Italy (of which 49 are cultural and five are natural) and 52 in China (of which 36 are cultural, 13 are natural and four are mixed). In fact, while in Italy, only nine sites (seven of which are cultural) include the word "rock" in the description, only one (natural) site description includes the word "underground" and four sites' (three cultural) descriptions refer to "cave", in China, this aspect is so remarkable that the word "rock" is present in the description of 18 sites (seven cultural, four mixed), "underground" in three (two cultural, one mixed) and "cave" in 13 (eight cultural, one mixed, five natural) descriptions.

The comparative approach shows substantial differences in the processes adopted for the valorization of two very similar systems, stimulating new research questions. With such a remarkably rich cultural heritage and strong cultural identity, why is China lagging behind in terms of the valorization process? And why is sustainable underground urban design not commonly practiced in Southern Italy, which is characterized by a wide range of temperatures, even though sustainability measures are in place for alternative energy sources, as the intensive installing of wind turbines in the area clearly demonstrates?

Is it possible to define mutual adjustments as a result of the present paper?

\section{From the Theoretical Approach to the Future for UBH}

On the basis of the considerations and results outlined above, our multidisciplinary research group carried out comparative research between Italy and China, dealing with the evaluation of best practices in the field of conservation, sustainable use and enhancement of underground rural villages with the aim of answering the above questions while stimulating mutual exchanges between China and Italy.

On one hand, the research focuses on the historical, typological and functional aspects of underground spaces within the urban context. On the other, it evaluates the social structure and the hierarchies in the local rural community, with the aim of raising awareness of the common cultural heritage and evoking participation in strategic planning for sustainable growth, based on the enhancement of cultural assets.

In China, this approach may be suitable for some rural villages of the Loess Plateau in Shanxy Region where historical UBH has not been compromised.

The comparison between the two systems also suggests that the valorization of Italian underground settlements can be improved with the re-introduction of functional "living space" in dismissed settlements and with the adoption of underground lifestyle concepts reaching a new frontier for sustainable house design. Perhaps not in Matera, where the current situation appears to be solidified, however in the abandoned villages of Gravina, Ginosa, Laterza, Palagiano, etc., actions in this direction to support local urban and social development could be successfully planned and implemented.

\section{Discussion and Conclusions}

Cave settlements in Italy and China-born as a common answer to the same natural and social obstacles, albeit in different historical, cultural and political contexts-are now at the core of projects that reflect substantial differences in approaches to cultural heritage and sustainable urban and rural development. While in Italy, all actions are geared towards Re-inventing, Re-introduction and Re-interpretation, in China, those three approaches are very weak and Re-building of new excavated settlements seems to be the nouvelle frontier of urban sustainability in karst habitat. This still depends 
on the underestimation of the role that these rural villages have had in the past and could have in the present as unique cultural landscapes that are full of character at the core of local identity and are exemplary of living heritage.

The analysis of the case studies and the local cultural policies in place in both countries shows that a mutual exchange between the eastern and the western approach would be useful. The western approach, mainly aimed at protecting the historical heritage during the process of fruition, valorization and reinterpretation, could benefit from the introduction of the historical living function and experimenting the new troglodyte trends in abandoned villages and selected areas. The eastern approach, on the other hand, could benefit from focusing much more on the valorization of UBH as a significant element of material and immaterial local cultural heritage.

Author Contributions: Conceptualization, L.G., R.V., L.L., F.F.; methodology, R.V., F.F.; formal analysis, L.G.; writing-original draft preparation, L.G., R.V., L.L., F.F.; writing-review and editing, L.G., R.V., L.L., F.F.; project administration, L.G., R.V., L.L.; funding acquisition, L.G., R.V., L.L.

Funding: This research was funded by the National Research Council of Italy (CNR) within the context of a Bilateral Agreement of Scientific and Technological Cooperation between the National Research Council of Italy (CNR) and the Chinese Academy of Cultural Heritage (CACH).

Acknowledgments: We thank Patricia Sclafani (CNR-ISSM) for her assistance with the language editing that greatly improved the manuscript.

Conflicts of Interest: The authors declare no conflict of interest.

\section{References}

1. Vegas, F.; Mileto, C.; Cristini, V.; Ruiz Checa, J.R. Underground cities. In Versus-Heritage for Tomorrow: Vernacular Knowledge for Sustainable Architecture; Correia, M., Dipasquale, L., Mecca, S., Eds.; Firenze University Press: Florence, Italy, 2014; pp. 114-123.

2. Varriale, R. Undergrounds in the Mediterranean: Ten urban functions from the "other" side of Mediterranean cultural heritage in a long-term perspective. Glob. Environ. 2014, 7, 198-245.

3. Porfyriou, H.; Genovese, L. China and Italy: Sharing Cultural Expertise; CNR: Rome, Italy, 2017.

4. Lapenna, V.; Leucci, G.; Parise, M.; Porfyriou, H.; Genovese, L.; Varriale, R. A project to promote the importance of the natural and cultural heritage of the underground environment in southern Italy. In Proceedings of the International Congress of Speleology in Artificial Caves, Cappadocia, Turkey, 6-10 March 2017; pp. 128-136.

5. Joint Research Projects CNR/CACH in the Triennium 2016-2018. Available online: https://www. cnr.it/en/bilateral-agreements/agreement/49/cach-chinese-academy-of-cultural-heritage (accessed on 7 December 2018).

6. Tropeano, M. Regional geology and stratigraphy of Matera and surroundings. In IGCP 369 Perimediterranean Palaeogeography Workshop; IGCP: Matera, Italy, 1999.

7. Tropeano, M.; Sabato, L.; Pieri, P. The Quaternary "post-turbidite" sedimentation in the South-Apennines Foredeep (Bradanic Trough-Southern Italy). Bollettino Soc. Geol. Ital. 2002, 1, 449-454.

8. Padula, M.; Motta, C.; Lionetti, G. Chiese e Asceteri Rupestri di Matera; De Luca: Rome, Italy, 1985.

9. Nugari, M.P.; Pietrini, A.M.; Caneva, G.; Imperi, F. Biodeterioration of mural paintings in a rocky habitat: The Crypt of the Original Sin (Matera, Italy). Int. Biodeterior. Biodegrad. 2009, 63, 705-711. [CrossRef]

10. Barger, M.S. The Conservation of Decorated Surfaces on Earthen Architecture. In Proceedings of the International Colloquium Organized by the Getty Conservation Institute and the National Park Service, Mesa Verde National Park, CO, USA, 22-25 September 2004.

11. Agnew, N. Conservation of Ancient Sites on the Silk Road. In Proceedings of the Second International Conference on the Conservation of Grotto Sites, Mogao Grottoes, Dunhuang, China, 28 June-3 July 2004.

12. Laureano, P. Giardini di Pietra, i Sassi di Matera e la Civiltà Mediterranea; Bollati Boringhieri: Torino, Italy, 1993.

13. Tropeano, M. Matera: Una serie di geositi urbani o una città geosito? Geologia dell'Ambiente 2003, 2003, 231-238.

14. Kapp, P.; Pullen, A.; Pelletier, J.D.; Russell, J.; Goodman, P.; Cai, F. From dust to dust: Quaternary wind erosion of the Mu Us Desert and Loess Plateau, China. Geology 2015, 43, 835-838. [CrossRef] 
15. Xinzeng, W.; Feng, J.; Xinping, L.; Shaoshan, A. The Loess Plateau. In Multifunctional Land-Use Systems for Managing the Nexus of Environmental Resoureces; Zang, L., Schwärzel, K., Eds.; Springer: Berlin, Germany, 2017; pp. 11-27.

16. Luvidi, L.; Fratini, F.; Rescic, S. Earth in Architecture: Traditional and Innovative Techniques of Conservation in Past and Present of the Earth Architectures in China and Italy; CNR: Rome, Italy, 2019.

17. Zhou, X. Conservation of Earthen Architecture Sites in China in Past and Present of the Earth Architectures in China and Italy; CNR: Rome, Italy, 2019.

18. Zhang, J. Experimental Conservation on Ruguanyao Kiln Site in Henan Province in China in Past and Present of the Earth Architectures in China and Italy; CNR: Rome, Italy, 2019.

19. Mattone, M.; Ibnoussina, M.; Rescic, S.; Fratini, F.; Magrini, D.; Mecchi, A.M.; Nocairi, M. Stabilization of earthen plasters: Exchange of knowledge and experiences between Italy and Morocco. J. Mater. Environ. Sci. 2016, 7, 3647-3655.

20. Mattone, M.; Rescic, S.; Fratini, F.; Manganelli Del, F. Experimentation of Earth-Gypsum Plasters for the Conservation of Earthen Constructions. Int. J. Archit. Herit. 2017. [CrossRef]

21. Varriale, R. Re-inventing underground space in Matera. In Proceedings of the 14th International Conference on Urban History (EAUH), Rome, Italy, 29 August-1 September 2018; Available online: https: / / eauh2018. ccmgs.it/ program/ (accessed on 18 January 2019).

22. Malcolm Wells 1926-2009. Available online: http:/ / www.malcolmwells.com/ (accessed on 7 December 2018).

23. Wells, M. The Earth-Sheltered House: An Architect's Sketchbook; Chelsea Green Publishing Company: White River Junction, VT, USA, 2009.

24. Wells, M. How to Build an Underground House; Visit Ogden: Ogden, UT, USA, 2009.

25. Broere, W. Urban underground space: Solving the problems of today's cities. In Tunnel and Underground Space Technology; Elsevier: Amsterdam, The Netherlands, 2016; pp. 245-248.

26. Risanamento dei "Sassi" di Matera-Atto Parlamentare della Camera dei Deputati n.2141 del 9 Agosto 1951. Available online: http:/ / www.camera.it/_dati/leg01/lavori/stampati/pdf/21410001.pdf (accessed on 7 December 2018).

27. Varriale, R. Southern underground space: From the history to the future. In Proceedings of the International Congress of Speleology in Artificial Caves, Cappadocia, Turkey, 6-10 March 2017; pp. 548-555.

28. Restauro Casa Matera. Available online: http://www.laureano.it/?news=restauro-casa-matera (accessed on 7 December 2018).

29. Giardini di Pietra. Available online: https://www.giardinidipietra.com/chi-siamo/ (accessed on 7 December 2018).

30. Wang, G.R. The Innovation and Development about Spatial form of Traditional Cave Dwellings in the Northwest. Adv. Mater. Res. 2014, 1008-1009, 1316-1319. [CrossRef]

31. Li, Z.G.; Sun, J. Study on the Green Ecological View of the Cave Dwellings and its Innovation and Development. Appl. Mech. Mater. 2013, 409-410, 377-380. [CrossRef]

32. Han, W.; Li, T. Ecological research configuration of cave architecture in Wang Yu village of Shanxi Province. BTAIJ 2014, 10, 4070-4079.

33. Golany, G.S. Chinese Earth-Sheltered Dwellings: Indigenous Lessons for Modern Urban Design; Hawai University Press: Honolulu, HI, USA, 1992.

34. Jiaping, L.; Wang, G.; Liu, Y. An Instance of Critical Regionalism: New Yaodong Dwellings in North-Central China. TDSR 2002, 13, 63-70.

35. Zan, L.; Yu, B.; Yu, J.; Yan, H. Heritage Sites in Contemporary China. In Cultural Policies and Management Practices; Routledge: London, UK, 2018.

(C) 2019 by the authors. Licensee MDPI, Basel, Switzerland. This article is an open access article distributed under the terms and conditions of the Creative Commons Attribution (CC BY) license (http:/ / creativecommons.org/licenses/by/4.0/). 